\title{
UTERINE LEIOMYOSARCOMA ASSOCIATED WITH CYSTIC ENDOMETRIAL POLYPS, CHONDRIOD METAPLASIA AND UTERINE HORN INTUSSUSCEPTION IN A GREATER CANE RAT (THRYONOMYS SWINDERIANUS)
}

\author{
Olusola Lawrence Ajayi ${ }^{1}$, Moshood Olajire Olaniyi ${ }^{1}$, Olugbenga Olayinka Alaka ${ }^{2}$, \\ Richard Edem Antia ${ }^{2}$, Temitope Morenikeji Oladipo ${ }^{1}$ \\ ${ }^{1}$ Department of Veterinary Pathology, College of Veterinary Medicine, \\ Federal University of Agriculture, Abeokuta, Nigeria \\ ${ }^{2}$ Department of Veterinary Pathology, University of Ibadan, Ibadan Nigeria
}

Received 5 November 2019; Received in revised form 5 March 2020; Accepted 20 April 2020

\begin{abstract}
A rare case of uterine leiomyosarcoma associated with chondriod metaplasia, cystic endometrial polyps and uterine horn intussusception in a greater cane rat was macroscopically, histopathologically, immuno-histochemically and ultrastructurally evaluated. The histopathological findings for this tumour were similar to those for leiomyosarcomas described in other species. Immunohistochemical examination demonstrated positive immunoreactivity of neoplastic cells with $\alpha$-smooth muscle actin, desmin and vimentin. Ultrastructurally, nuclear and cytoplasmic features were consistent with leiomyosarcoma. These results revealed the tumour to be of smooth muscle origin. To our knowledge, this is the first reported case of uterine leiomyosarcoma associated with cystic endometrial polyps, chondriod metaplasia and uterine horn intussusception in a greater cane rat.
\end{abstract}

Key words: uterine leiomyosarcoma, endometrial polyps, chondriod metaplasia, uterine horn intussusception, Greater cane rat

\section{INTRODUCTION}

The domestication of the greater cane rat (Thryonomys swinderianus) for human consumption has thrived over the years in western, central and eastern Africa (1). This has been attributed to the low protein consumption of the teeming population in these regions. However, there is an absence of knowledge about the management and diseases associated to these species. Various infectious and non-infectious conditions have been documented in this animal (1). But neoplasms in

Corresponding author: Dr. Olusola Lawrence Ajayi, $\mathrm{PhD}$

E-mail address: alabsola@yahoo.com

Present address: Department of Veterinary Pathology, College of

Veterinary Medicine, Federal University of Agriculture Abeokuta,

Nigeria

Phone: +2348068783895

Copyright: (C) 2020 Ajayi O.L. This is an open-access article published under the terms of the Creative Commons Attribution License which permits unrestricted use, distribution, and reproduction in any medium, provided the original author and source are credited.

Competing Interests: The authors have declared that no competing interests exist.

Available Online First: 29 May 2020

Published on: 15 October 2020

https://doi.org/10.2478/macvetrev-2020-0019 these species are seldom encountered, especially tumours of the female reproductive tract (2). Uterine leiomyosarcoma is a malignant tumour of the smooth muscle of the uterus (3). Benign mesenchymal tumours such as leiomyoma, fibroma or fibroleiomyoma are most common in the dog and may affect the uterus, cervix or vagina (3). Malignant mesenchymal tumours of the uterus are very rare but leiomyosarcoma, fibrosarcoma and lymphoma have been reported occasionally in cats (4). Reports on uterine leiomyoma in a captive elephant (5) and uterine fibroleiomyoma in the Asian elephant $(6,7)$ have been documented in the wild.

Endometrial polyps or uterine polyps are benign growths that are oval or round in shape and remain attached to the uterine wall by a large base or a thin stalk and project into the lumen of the affected uterus as sessile or pedunculated masses emanating from the endometrium. Endometrial polyps are uncommon conditions in humans (8) and laboratory rats (9). Jori and Cooper (2) diagnosed a chondroma in an adult 
female, a haemangiosarcoma in a subadult male, and a chondrosarcoma in an elderly female greater cane rat. To our knowledge, neoplasms of the reproductive tract in this species have not been documented. Thus, this case report describes uterine leiomyosarcoma associated with chondriod metaplasia, endometrial polyps and uterine horn intussusception in a greater cane rat.

\section{MATERIAL AND METHODS}

The subject was a 2 years-old, female, blacktan, greater cane rat (Thryonomys swinderianus), weighing approximately $3.5 \mathrm{~kg}$, which was brought from the Cane Rat Unit of the College of Environmental Resources and Management, Federal University of Agriculture, Abeokuta, to the Department of Veterinary Pathology of the same University for postmortem examination. The animal was found dead without any premonitory sign, except for a slight mucoid vaginal discharge and anuria of about 4 days. There was no history of oestrogen-based medicament or exposure to other progestins or estrogenic plants. Necropsy was performed and gross morphological alterations from affected organs were documented. Tissues such as uterine horn and body, endometrial polyps, liver, lung, spleen and kidneys were harvested and fixed in $10 \%$ buffer formalin, dehydrated in graded levels of alcohol, embedded in paraffin wax, sectioned at $5 \mu \mathrm{m}$ and stained with haematoxylin and eosin. This was evaluated under the light microscope.

To determine the cellular origin of the neoplastic masses, immunohistochemistry and electron microscopy were performed. For immunohistochemistry, briefly, sections of the uterine mass were deparaffinized, hydrated and heated to retrieve antigen in $0.01 \mathrm{M}$ citrate buffer ( $\mathrm{pH}$ 6.0) for 20 minutes in a microwave oven and allowed to cool for 20 minutes at room temperature. Sections were immersed in $3 \% \mathrm{H}_{2} \mathrm{O}_{2}$ in methanol to quench endogenous peroxide. Thereafter, normal goat serum (Histomark, U.S.A) was added and incubated at room temperature $\left(280-300^{\circ} \mathrm{C}\right)$ for 30 minutes. Diluted primary antibodies for mouse monoclonal anti-vimentin (DAKO U.S.A; 1:100), mouse monoclonal anti-desmin (DAKO U.S.A; 1:100), mouse monoclonal anti-smooth muscle actin (DAKO U.S.A; 1:50) were then applied to the sections. Thereafter, sections were incubated with secondary antibody supplied by KLP (Avidin-Biotin complex) kit (Histomark, U.S.A) for 30 minutes at room temperature. Sections were finally visualized with 3, 3'-diaminobenzidine and counterstained with Meyer's haematoxylin.

For the electron micrograph, the tumour tissues were cut into small pieces $(0.5 \mathrm{~mm}$ in diameter) and immediately fixed in $2.5 \%$ glutaraldehyde in $0.1 \mathrm{M}$ phosphate buffer at $\mathrm{pH}$ 7.4. Post-fixation was carried out in $1 \%$ osmium tetroxide in $0.15 \mathrm{M}$ phosphate buffer at $\mathrm{pH} 7.3$ for 3 hours. The specimens were washed in $0.15 \mathrm{M}$ phosphate buffer at $\mathrm{pH} 7.3$, dehydrated in graded levels of ethanol from $30 \%$ to $75 \%$, transferred to propylene oxide, infiltrated with a 1:1 mixture of propylene oxide and Epon resin overnight, then embedded in Epon. After trimming the blocks, sections were made on a Porter-Blum MT-2 microtome with a diamond knife. The sections were mounted on coated copper grids and stained with 2\% uranyl acetate and lead citrate. The grids were observed under an EM109 electron microscope and photographed.

\section{RESULTS}

At necropsy, the abdomen was slightly distended and the abdominal cavity contained a moderate amount of serosanguinous fluid (approximately $20 \mathrm{ml}$ ). Most of the organs including the lung, spleen, heart and liver were grossly normal. Telescoping of the lower segment of the right uterine horn (about $5 \mathrm{~cm}$ ) into itself with involvement of the uterine body and marked congestion of the mesosalpinx was observed (Fig. 1).

The uterine body was moderately enlarged and the blood vessels on the serosal surface were engorged and prominent. On the right side of the upper endometrium, close to the entrance of the right uterine horn were two grayish white unencapsulated, pedunculated spherical masses of different sizes $(2 \mathrm{~cm} \times 1.2 \mathrm{~cm}$ and $1 \mathrm{~cm} \times 0.5 \mathrm{~cm})$ (Fig. 2).

The masses were soft and rubbery, and protruded into the uterine lumen. The two masses were poorly demarcated and obliterated the normal uterine endometrial architecture. The cut surface was glistening and smooth, with slightly interwoven muscle fibers. No metastases were observed in other organs. At the lower portion of the uterine body, the endometrium was moderately thickened by numerous penduculated and unencapsulated grayish tan, soft and oedematous masses (Fig. 2). Other significant gross findings included markedly distended (with urine) and non-patent urinary bladder, and rough, pitted and granular cortical surface of the kidneys. The pelvis and calyxes 


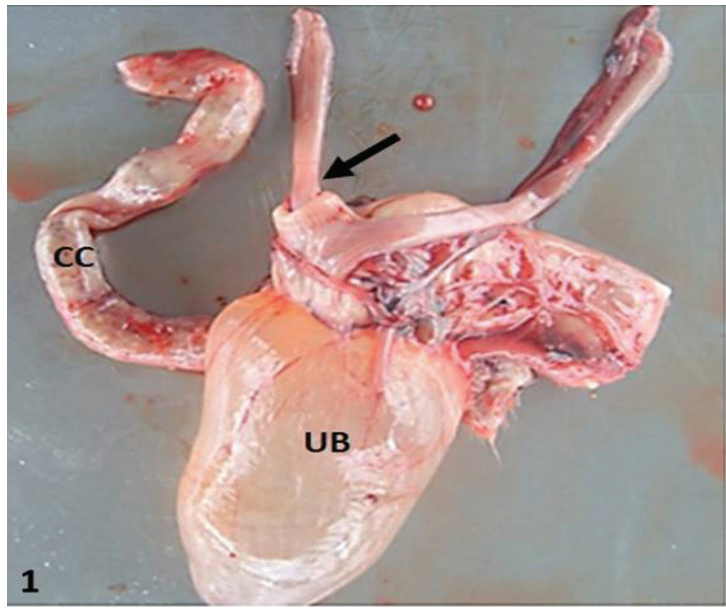

Figure 1. Uterus showing telescoping of the lower segment of the right uterine horn into the uterine body (arrow) with caecum (CC) and distended urinary bladder (UB)

were markedly distended with watery gel-like materials. A tentative diagnosis of uterine horn intussusceptions secondary to uterine leiomyoma and endometrial polyps was made.

Histopathologically, neoplastic mass showed densely populated interlacing bundles of smooth muscle cells that were not well-differentiated. The nuclei were oval, fusiform and spindleshaped with blunt ends. The nuclei also revealed margination of chromatin and indistinct nucleoli. Multiple multinucleated giant cells

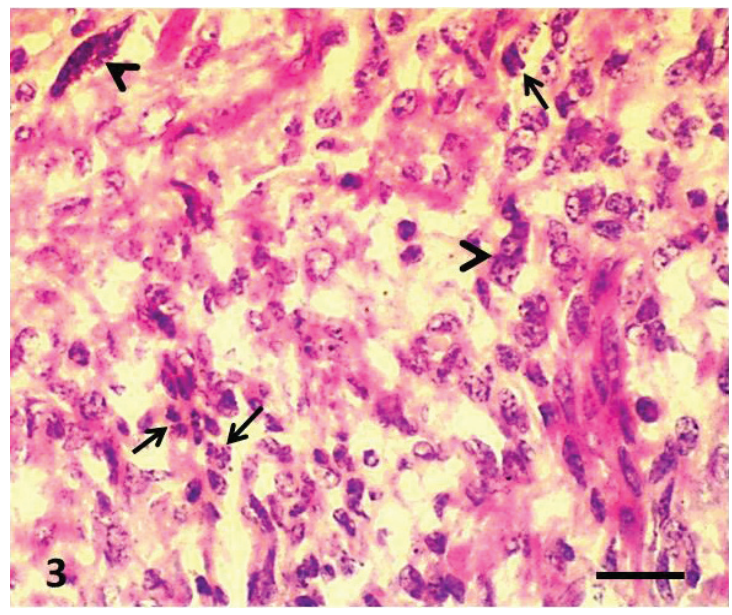

Figure 3. Uterine leiomyosarcoma showing proliferation of atypical anaplastic spindle-shaped cells with blunt-ended nuclei, interlacing cords and numerous bizarre mitotic figures (arrows) and multinucleated giant cells (arrow heads). H\&E; Bar $=50 \mu \mathrm{m}$

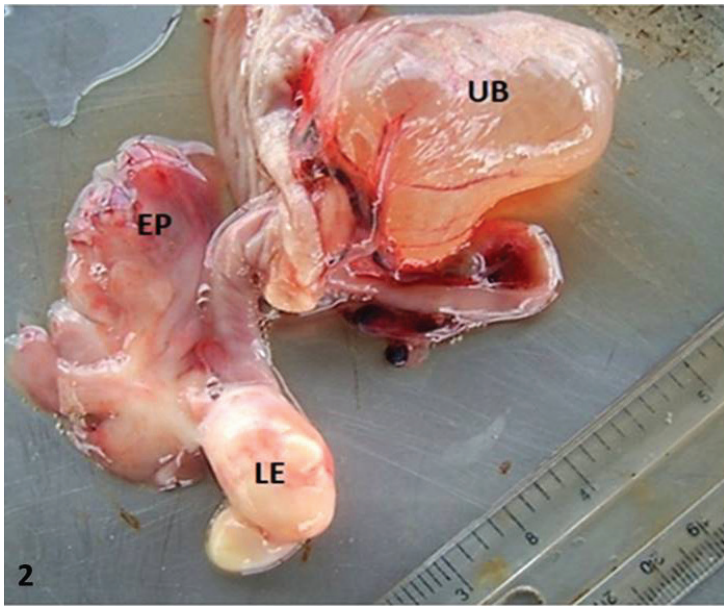

Figure 2. Uterus showing the 2 masses of leiomyosarcoma (LE), endometrial polyps (EP) and the distended Urinary bladder (UB)

were observed. The cytoplasm was deeply eosinophilic and vacuolated in some cells. Cell borders were indistinct. There were high nucleicytoplasmic ratio, marked cellular and nuclear pleomorphism, hyperchromasia and bizarre mitotic figures. The mitotic index ranged from 5 to 8/HF. Multiple foci of myolysis were observed along with a few inflammatory cells (mostly lymphocytes, macrophages and plasma cells). Vascular invasion of the neoplastic cells was not observed (Fig. 3 and 4).

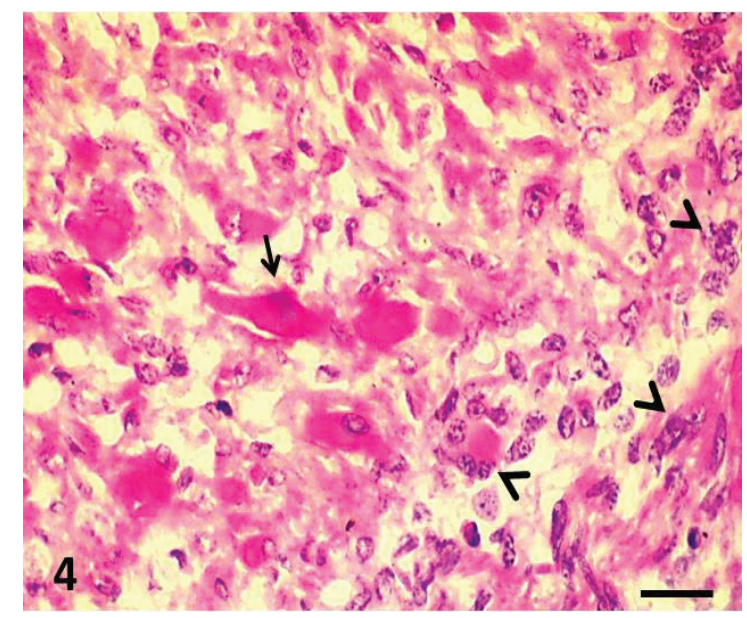

Figure 4. Uterine leiomyosarcoma showing proliferation of atypical anaplastic cells with foci of mild necrotic myofibres (arrow) and multinucleated giant cell (arrow heads). H\&E; Bar $=50 \mu \mathrm{m}$ 


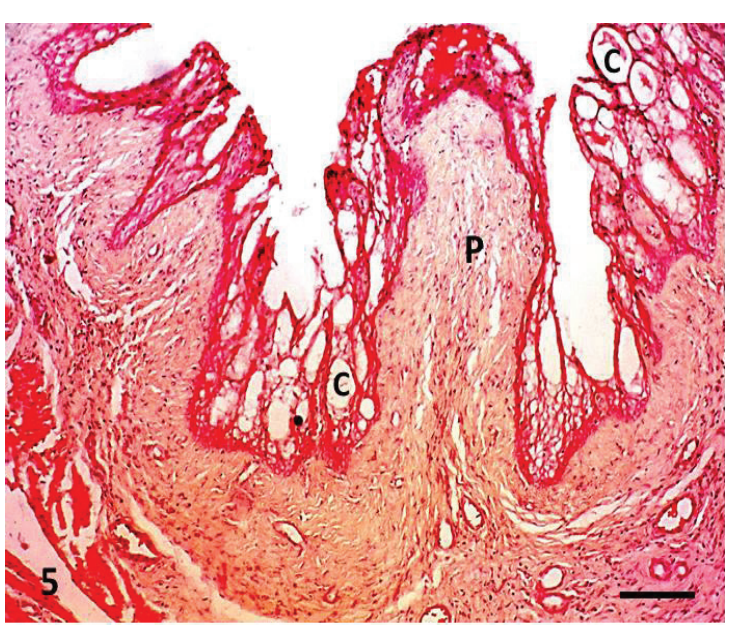

Figure 5. Uterine polyps. Polyps $(\mathrm{P})$ emanating from the myometrium into the uterine lumen with cystic dilatation (C) at the upper part of the polyps. H\&E; Bar $=250 \mu \mathrm{m}$

The endometrial polyps consisted of smooth muscles fibres with their roots within the myometrium and their tips covered with low cuboidal epithelial lining and extended into the uterine lumen. Cystic dilatations of the endometrial lining were also observed (Fig. 5).

There was also a formation of chondrocytes at the upper part of the polyps (Fig. 6). Other extrauterine histopathological changes included tubular and glomerular cast, severe dilatation of the renal tubules and necrosis of the tubular epithelial cells with numerous oxalate crystals.

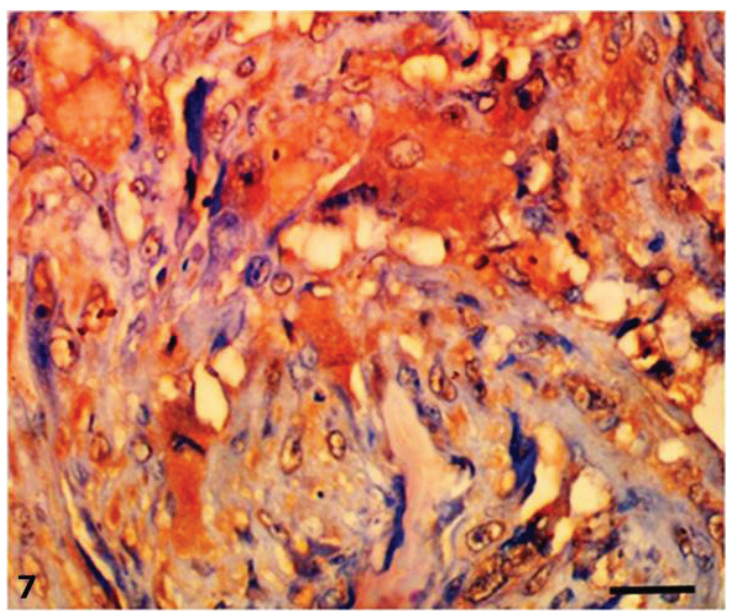

Figure 7. Immunohistochemistry, Uterus, Greater Cane rat. The neoplastic cells showed positive cytoplasmic immunoreactivity with alpha smooth muscle actin antibody. IHC; Bar $=50 \mu \mathrm{m}$

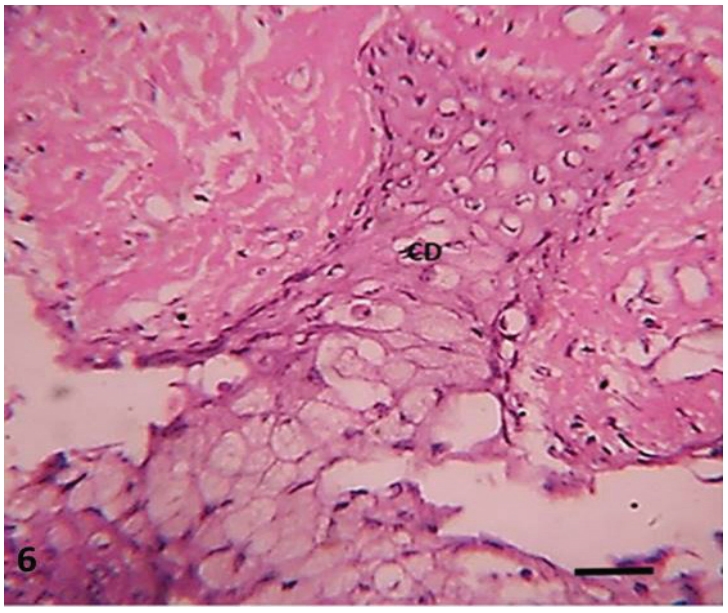

Figure 6. Endometrial polyps showing the formation of chondrocytes (CD) within tip of the polyps (CD). $\mathrm{H} \& \mathrm{E} ; \mathrm{Bar}=50 \mu \mathrm{m}$

Immunohistochemical studies revealed strong positive cytoplasmic immunoreactivity to antialpha smooth muscle actin protein (Fig. 7) and moderate cytoplasmic staining to anti-desmin (Fig. 8) and slight immunoreactivity to anti-vimentin protein (Fig. 9).

Ultrastructural changes consisted of irregularly oriented, pleomorphic smooth muscle cells with characteristic spindle shapes, containing varying numbers of cytoplasmic organelles. Most of the nuclei were disproportionately large, blunted, and oval-round shaped, often with irregular or

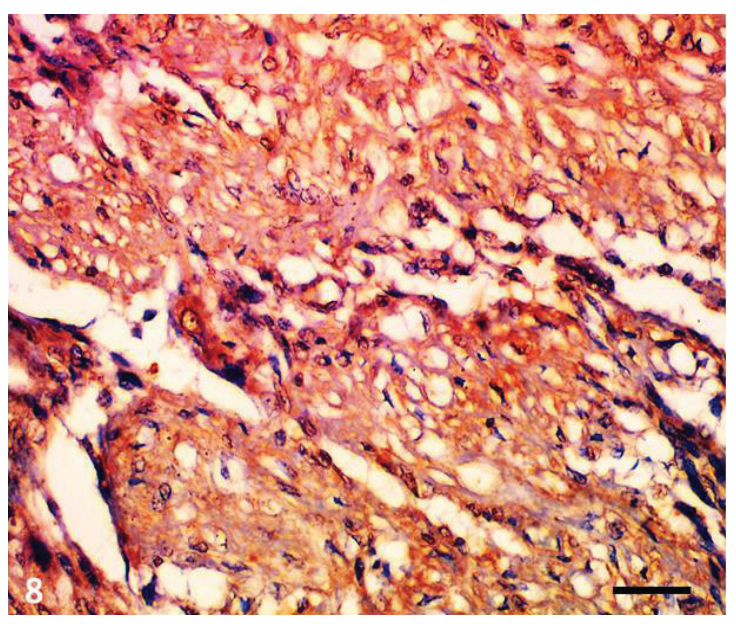

Figure 8. Immunohistochemistry, Uterus, Greater Cane rat. The neoplastic cells showing positive cytoplasmic immunoreactivity with anti-desmin protein antibody. IHC; Bar $=50 \mu \mathrm{m}$ 


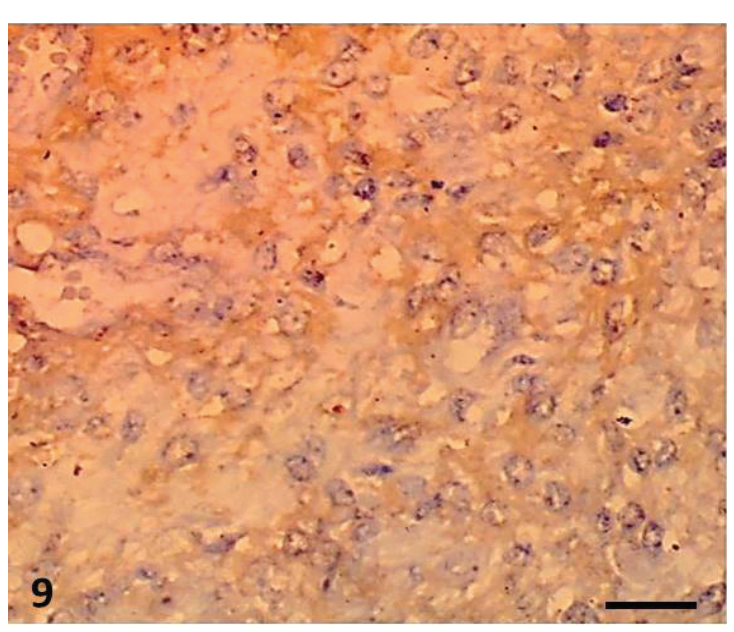

Figure 9. Immunohistochemistry, Uterus, Greater Cane rat. The neoplastic cells showing positive immunoreactivity with anti-vimentin protein antibody. $\mathrm{IHC}$; Bar $=50 \mu \mathrm{m}$

indented nuclear membranes. The indentation in some cells almost sub-divided the nuclei. In many instances, two or more nuclei were found in a single cell. The nuclear chromatin appeared to be randomly dispersed and completely marginated in some cells. The nucleoli were often prominent and centrally placed, with homogenous osmiophilic material. In the cytoplasm, mitochondria were sparsely dispersed. Numerous free ribosomes were distributed but appeared to be diminished

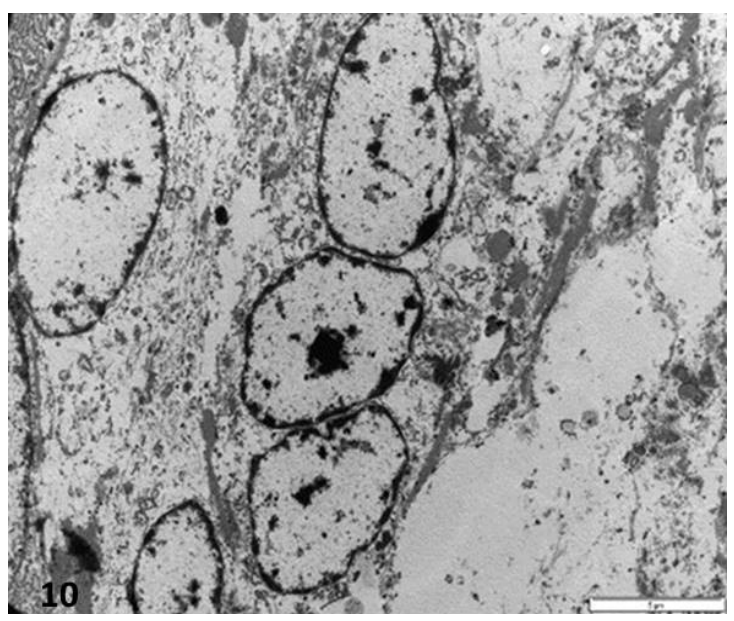

Figure 10. Ultrastructural changes in leiomyosarcoma cell containing 3 prominent nuclei, light cytoplasmic matrix with free ribosomes, rough endoplasmic reticulum, mitochondria and scattered small bundles of myofilaments. Bar $=5 \mu \mathrm{m}$ in some cells. Abundant rough endoplasmic reticulum was seen; some were dilated and contained an osmiophilic electron-dense material (Fig. 10).

Most of the cells contained very fine myofilaments arranged in bundles with periodic spindle densities, oriented in a disorganized manner (Fig. 11). The myofilaments were sparsely distributed and parallel to the nuclei or along plasma membranes. Individual thread-like filaments were scattered within a clear amorphous cytoplasmic substance.

\section{DISCUSSION}

The gross and histopathological changes observed in this condition were in agreement with other reports in domestic and wild animals with uterine leiomyosarcoma $(10,11)$. However, the occurrence or the combination of uterine leiomyosarcoma, uterine horn intussusception, chondroid metaplasia and endometrial polyps are rare findings in previous reports, although, uterine leiomyosarcoma with osteoclast-like formation has been reported in humans (12). To the best of the authors' knowledge, this is the first reported case of uterine horn intussusception secondary to uterine leiomyosarcoma with chondriod metaplasia and endometrial polyps in domestic or in wild animals.

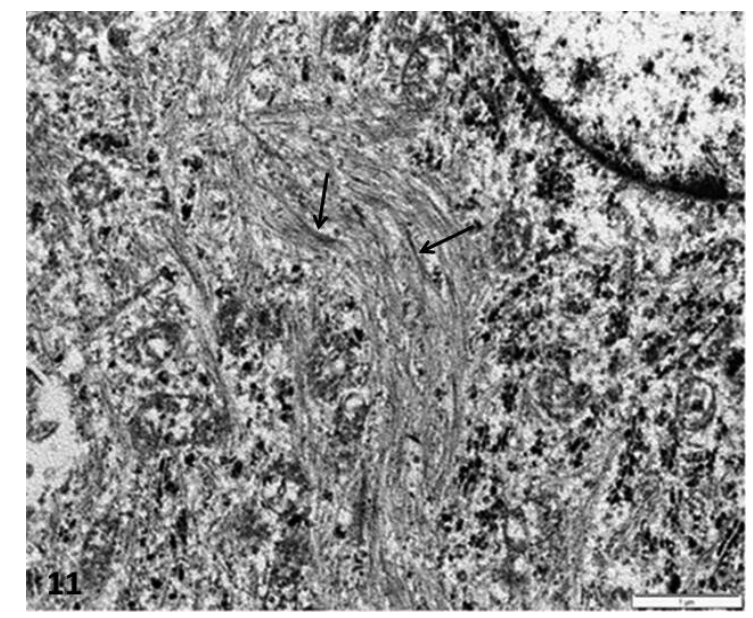

Figure 11. Ultrastructure of leiomyosarcoma characterized by loosely arranged fine myofilaments in bundles with disorganised periodic spindle densities (arrows) and numerous mitochondria with free ribosomes. Bar $=5 \mu \mathrm{m}$ 
Various aetiological agents and factors have been suggested to induce neoplasms in rodents such as a high inbreeding coefficient, an oncogenic virus, or chemicals and steroidal hormones (2). In this report, the aetiology of this condition is uncertain, since there was no history of oestrogenbased medicament nor estrogenous plants fed to them, but it is possible that the tumour occurred as a result of transformational change of uterine smooth muscle over time or as a result of inbreeding within the colony or the animal might have been exposed to an unknown carcinogen. It is also possible that persistent stimulation of steroidal hormones secreted by the ovary would have been responsible for this neoplastic change. Regrettably, the ovaries of this animal were not examined to confirm this assertion.

The effect of this tumour on reproductive fertility is not known, as the parity or reproductive status of the cane rat was not given in the history. Uterine tumours that formed intraluminal polypoid growths have been shown to impede fertility in zoo felids (13) and uterine leiomyomas have been suspected to impede fertility in primates, dogs and horses $(14,15,16)$. In this report, we assume that the leiomyosarcoma at the bifurcation of the uterus body and the uterine 'polyps observed could have impeded the movement of the ova, their fertilization and implantation on the uterine endometrium.

Previous reports have shown the difficulties in making the difference between the welldifferentiated leiomyosarcoma and leiomyoma. It has been suggested that high mitotic index, invasiveness of the tumour, cellular atypia and tumour necrosis are the significant features of leiomyosarcoma in differentiating it from leiomyoma $(17,18,19)$. In this report, malignant features such as cellular pleomorphism, high mitotic index, cellular atypia, foci of necrosis and giant cell formation are suggestive of leiomyosarcoma rather than leiomyoma.

In humans, metastases of leiomyosarcoma to distant sites have been reported in the lung, brain, skin, thyroid, salivary gland, heart, liver, pancreas, adrenal gland, bowel, breast and bone $(20,21)$. In this report, there was no metastasis nor invasion of the surrounding tissues, but the characteristic features of malignancy such as high cellular pleomorphism, prominent cellular atypia, necrotic foci, moderate number of mitotic figures, multinucleated giant cells and undifferentiated appearance of the mass were evident. This is in accordance with the reports of other workers who asserted that not all leiomyosarcoma metastasize (13).
The cause of the markedly distended urinary bladder and hydronephrosis in this report is also unknown but it might be due to compression of the inner part of the vagina by the uterine mass or due to the obstruction of the urinary tract by uroliths which consequently led to urine retention in the kidney to cause hydronephrosis (22).

The occurrence of uterine horn intussusception in this animal is also a rare finding in both humans and domestic animals. There is paucity of information on this pathological change. The aetiology of the uterine horn intussusception is unknown, but it might be speculated that the expanding leiomyosarcoma at the entrance of the right uterine horn which possibly obstructed the normal movement of the uterine smooth muscle led to the telescoping of the lower part of the uterine horn segment into the uterine body. Uterine torsion has been documented in the cat (23), uterine prolapse in Richardson's ground squirrel (Spermophilus richardsonii) (24), while oviductal volvulus and lymphangiectasia have been reported in Nera-black chickens $(25,26)$, but reports on uterine horn intussusception are rare, and to the best of our knowledge, this is the first reported case of uterine horn intussusception in wild or domestic animals.

In our case, the actual cause of death is unknown but we assume that renal failure and hypovolemic shock were the immediate causes of death. This is obvious by the anuria, hydronephrosis, tubular destruction by the oxalate crystals and the bloodtinged hydroperitonium.

The expression of positive immunoreactivities to smooth muscle actin, desmin and vimentin proteins in this report confirmed uterine leiomyosarcoma and is consistent with previous case reports of leiomyosarcoma in hamster (27) and in wild rat (28). The ultrastructural changes described in this case report such as myofibres containing 2-3 prominent nuclei; light cytoplasmic matrix containing free ribosomes, rough endoplasmic reticulum, mitochondria and some showing loosely arranged fine myofilaments bundles with disorganized periodic spindle densities are consistent with previous reports (29) in which uterine leiomyosarcoma was diagnosed.

\section{CONCLUSION}

This case report describes the gross, histopathological, immunohistochemical, and ultrastructural features of uterine leiomyosarcomas in a 2-year-old greater cane rat with uterine 
horn intussusception, chondroid metaplasia and endometrial polyps. The neoplasm was confirmed as being of smooth muscle origin based on tumour cell morphology, positive immunoreactivity with $\alpha$-smooth muscle actin, desmin and vimentin as well as ultrastructural features consistent with uterine leiomyosarcoma. This study, to the best of our knowledge, confirms the first reported case of uterine leiomyosarcoma associated with endometrial polyps, chondriod metaplasia and uterine horn intussusception in a greater cane rat. The report also suggests that in cane rats presented with a history of anuria and prolong mucous discharge from the vulva, uterine leiomyosarcoma with endometrial polyps should be considered as a differential diagnosis.

\section{CONFLICT OF INTEREST}

The authors declared that they have no potential conflict of interest with respect to the authorship and/or publication of this article.

\section{ACKNOWLEDGEMENTS}

The authors would like to thank Dr. L Du Plessis and Ms A.Lensink at the electron microscopy unit, Department of Veterinary Anatomy, University of Pretoria South Africa, Onderstepoort for their technical help.

\section{AUTHORS' CONTRIBUTIONS}

OLA participated in the postmortem, performed immunohistochemistry, transmission electron microscopy and contributed immensely to the writing of the manuscript; MOO and OOA participated in the postmortem and writing; REA participated in the histopathology and the manuscript writing; TMO participated in the immunohistochemistry.

\section{REFERENCES}

1. Jori, F., Cooper, J.E., Casal, J. (2001a). Postmortem findings in captive cane rats (Thryonomys swinderianus) in Gabon. Veterinary Record 148(20): 624-628.

https://doi.org/10.1136/vr.148.20.624

PMid:11394798

2. Jori, F., Cooper, J.E. (2001b). Spontaneous neoplasms in captive african cane rats (Thryonomys swinderianus Temminck, 1827). Vet. Pathol. 38, 556-558.

https://doi.org/10.1354/vp.38-5-556

PMid:11572565
3. Mozzachio, K., Linder, K., Dixon, D. (2004). Uterine smooth muscle tumors in potbellied pigs (Sus scrofa) resemble human fibroids: a potential animal model. Toxicol Pathol. 32, 402-407. https://doi.org/10.1080/01926230490440880 PMid:15307213

4. Bagley, R.S., Levy, J.K., Malarkey, D.E. (1996). Hypoglycemia associated with intra- abdominal leiomyoma and leiomyosarcoma in six dogs. J Am Vet Med Assoc. 208(1): 69-71.

5. Mumba, C., Pandey, G.S., Kabali, E., Shibahara, T., Kubo, M. (2011). Uterine fibroleiomyoma in a 12 year old sow. Indian J Vet Pathol. 35(1): 84-86.

6. Sapundzhiev, E., Pupaki D., Zahariev P., Georgiev G., Ivanov I., (2007). Fibroleiomyoma in elephant uterus. J Vet Med Series A. 54 (9): 499-500.

https://doi.org/10.1111/j.1439-0442.2007.00949.x PMid:17931224

7. Pringproa, K., Madarame, H., Sritun, J., Bumpenpol, P., Pedsri, P., Somgird, C. Thitaram, C. (2015). Histopathological and immunohistochemical characterization of spontaneous uterine leiomyomas in two captive Asian Elephants. Thai J Vet Med. 45(2): 289-294.

8. Assikis, V.J., Neven, P., Jordan, V.C., Vergote, I. (1996). A realistic clinical perspective of tamoxifen and endometrial carcinogenesis. Eur $\mathrm{J}$ Cancer. 32A(9): 1464-1476. https://doi.org/10.1016/0959-8049(96)00184-0

9. Walsh, K.M., Poteracki, J. (1994). Spontaneous neoplasms in control Wistar rats. Fundam Appl Toxicol. 22(1): 65-72. https://doi.org/10.1093/toxsci/22.1.65

10. Meuten, D.J. (2002). Tumors in domestic animals. 4th ed. (p.788). Iowa State: University of California. https://doi.org/10.1002/9780470376928

11. Silva, A.E., Ocarino, N.M., Cassali, G.D., Nascimento, E.F., Coradini, M.A., Serakides, R. (2006). Uterine leiomyoma in chimpanzee (Pan troglodytes). Arq Bras Med Vet Zootec. 58(1): 129132. https://doi.org/10.1590/S0102-09352006000100020

12. Terasaki, M., Terasaki, Y., Yoneyama, K., Kuwahara, N., Wakamatsu, K., Nagahama, K., Kunugi, S., Takeshita, T., Shimizu A. (2015). Uterine leiomyosarcoma with osteoclast-like giant cells associated with high expression of receptor activator of nuclear factor $\mathrm{\kappa B}$ - ligand. Hum Pathol. 46(11): 1679-1684. https://doi.org/10.1016/j.humpath.2015.04.018 PMid:26315618 
13. Chassy, L.M., Gardner, I.A., Plotka, E.D., Munson L. (2002). Genital tract smooth muscle tumors are common in zoo felids but are not associated with melengestrol acetate contraceptive treatment. Vet Pathol. 39(3): 379-385.

https://doi.org/10.1354/vp.39-3-379

PMid:12014502

14. Verkauf, B.S. (1992). Myomectomy for fertility enhancement and preservation. Fertil Steril. 58(1): 1-15. https://doi.org/10.1016/S0015-0282(16)55128-0

15. Moody, K.D., Weir, E.C., Morgenstern, S.E., Barthold S.W. (1996). Resumption of fertility after myomectomy for uterine leiomyoma in a rhesus macaque. Lab Anim Sci. 46(1): 120- 122.

16. Santschi, E.M., Slone, D.E. (1994). Successful pregnancy after partial hysterectomy in two mares. J Am Vet Med Assoc. 205(8): 1180-1182.

17. Joel, R. L., Micheal, P. J. (1990). Oviduct, uterus, and vagina. In: G.A. Boorman, S. L. Eustis, M. R. Elwell (Eds.), Pathology of the Fischer rat - Reference and atlas (pp. 443459). San Diego: Academic Press.

18. Anisimov, V. N., Nikonov, A. A. (1990). Tumours of the vagina, uterus and oviduct. In : V.S. Turusov, U. Mohr (Eds.), Pathology of tumours in laboratory animals (pp. 445-471). Oxford: Oxford University Press.

19. Cooper, B.J., Valentine, B.A. (2002). Tumors of muscles. In : D. J. Meuten, (Ed), Tumor in domestic animals (pp. 319-363). Ames: Iowa State Press. https://doi.org/10.1002/9780470376928.ch6 PMid:18246071

20. Tirumani, S.H., Deaver, P., Shinagare, A.B., Tirumani, H., Hornick, J.L., George, S., Ramaiya, N.H. (2014). Metastatic pattern of uterine leiomyosarcoma: retrospective analysis of the predictors and outcome in 113 patients. J Gynecol Oncol. 25(4): 306-312.

https://doi.org/10.3802/jgo.2014.25.4.306

PMid:25142630 PMCid:PMC4195301

21. Bartosch, C., Mariana, A. Ana, S., Pires, L., Galaghar, A., Guimaraes, M. Antunes, L.J., Lopes, M. (2017). Distant metastases in uterine leiomyosarcomas: the wide variety of body sites and time intervals to metastatic relapse. Int J Gynecol Pathol. 36(1): 31-41.

https://doi.org/10.1097/PGP.0000000000000284 PMid:27015437
22. Ochi, F., Furuno, K., Chong, P., Tezuka, J., Mizuno, Y., Aoki, T., Ishii, E. (2017). Bilateral hydronephrosis due to obstructive ureteral stone associated with norovirus gastroenteritis. Clinical Case Reports 5(6): 936-938.

https://doi.org/10.1002/ccr3.952

PMid:28588843 PMCid:PMC5458008

23. Kuroda, K., Osaki, T., Harada, K., Yamashita, M., Murahata, Y., Azuma, K., Tsuka, T., Ito, N., Imagawa, T., Okamoto, Y. (2017). Uterine torsion in a full-term pregnant cat. JFMS Open Reports. 3(2). https://doi.org/10.1177/2055116917726228 PMid:28839948 PMCid:PMC5564926

24. Proulx, G., Keith, M., Neil, M., Benjamin, P. (2009). Uterine prolapse in an adult Richardson's ground squirrel (Spermophilus richardsonii). Canadian Field-Naturalist. 123(4): 370-371.

https://doi.org/10.22621/cfn.v123i4.1006

25. Ajayi, O.L., Antia R.E., Omotainse, S.O. (2008). Oviductal volvulus in a Nera black chicken (Gallus gallus domesticus) in Nigeria. Avian Pathol. 37(2): 139-140.

https://doi.org/10.1080/03079450801895324 PMid:18393090

26. Ajayi, O.L., Antia, R.E. (2010). Oviductal lymphangiectasia secondary to mesosalphinx leiomyoma in a chicken (Gallus gallus domesticus) a case report. Vet Arhiv. 80(1): 155-161.

27. Yi, J.Y., Kim, Y.H., Yoon, B.I. (2008). Primary subcutaneous leiomyosarcoma of the hamster hind leg. J Vet Med Sci. 70(5): 517-520.

https://doi.org/10.1292/jvms.70.517

PMid:18525178

28. Jeon, B.S., Kim, H.G., Lee, B.W., Han, J.H., Yoon, B.I. (2013). Uterine leiomyosarcoma in a wild rat (Rattus norvegicus): usefulness of Ki-67 labeling index for diagnosis. Lab Anim Res. 29(2): 127-130. https://doi.org/10.5625/lar.2013.29.2.127 PMid:23825485 PMCid:PMC3696625

29. Vemireddi, V., Ingeborg, M., Langohr, H., Thacker, L. (2007). Polypoid uterine leiomyosarcomas in a sheep. J Vet Diagn Invest. 19(3): 309-312. https://doi.org/10.1177/104063870701900316 PMid:17459865 